\title{
CALIDAD MICROBIOLÓGICA Y USOS DEL AGUA SUBTERRÁNEA EN ESTABLECIMIENTOS AGROPECUARIOS DEL CENTRO-SUR DE CÓRDOBA, ARGENTINA
}

Microbiological quality and uses of groundwater in the agricultural farms in the central-south area of Córdoba, Argentina

\author{
Noelia Luján URSELER ${ }^{1}$, Romina Andrea BACHETTI ${ }^{1}$, Gabriela DAMILANO ${ }^{2}$, \\ Verónica MORGANTE ${ }^{3}$, Rosa Natalia INGARAMO ${ }^{1}$, Verónica SAINO $^{1}$ y Carolina Andrea MORGANTE ${ }^{1 *}$
}

${ }^{1}$ Instituto Académico Pedagógico de Ciencias Básicas y Aplicadas, Universidad Nacional Villa María, Arturo Jauretche 1555, Villa María, Córdoba, Argentina, C.P. 5900

${ }^{2}$ Departamento de Educación, Facultad de Ciencias Humanas. Universidad Nacional de Río Cuarto. Ruta Nac. 36 - km. 601, Río Cuarto, Código Postal 5804, Córdoba, Argentina

${ }^{3}$ Programa Institucional de Fomento a la Investigación, Desarrollo e Innovación. Universidad Tecnológica Metropolitana. Ignacio Valdivieso 2409, San Joaquín, Santiago, Chile

*Autora para correspondencia: cmorgante@unvm.edu.ar

(Recibido: abril 2018; aceptado: enero 2019)

Palabras clave: acuífero freático, sistemas productivos agrícolas, contaminación, indicadores biológicos

\section{RESUMEN}

La intensificación de los sistemas productivos (agrícolas o ganaderos) ha provocado una alteración en la calidad del agua subterránea debido, entre otras causas, a la introducción de microorganismos contaminantes. La calidad microbiológica del agua debe considerarse como un parámetro elemental para definir su aptitud para diferentes usos: consumo de la población rural, consumo del ganado bovino o limpieza de instalaciones de ordeñe. Los objetivos de este estudio fueron: (1) conocer la calidad microbiológica del agua subterránea en establecimientos agropecuarios para definir aptitudes de uso y (2) evaluar la relación entre el uso del suelo y la calidad del agua subterránea de la región. Se realizaron análisis microbiológicos utilizando como indicadores: $i$ ) recuento de bacterias aerobias mesófilas, ii) detección de coliformes totales y fecales, y iii) presencia de Escherichia coli y Pseudomonas aeruginosa en muestras de agua obtenidas de perforaciones de establecimientos agrícolas $(\mathrm{EA} ; \mathrm{n}=28)$ o ganaderos/lecheros (EG; $\mathrm{n}=34$ ) ubicados en la región centro-sur de la provincia de Córdoba, Argentina. En el $58 \%$ de las muestras analizadas $(\mathrm{n}=62)$ se detectó la presencia de al menos un indicador de contaminación que supera los parámetros para consumo humano o higiene de instalaciones de ordeñe. El $12 \%$ de los EG poseen agua de calidad deficiente para el consumo del ganado bovino. Mediante análisis bivariados se encontró una escasa asociación entre el uso del suelo y la calidad microbiológica del agua, por lo que el origen de la contaminación observada responde a múltiples factores que inciden en la región.

Key words: phreatic aquifer, agricultural productive systems, contamination, biological indicators 


\begin{abstract}
The productive systems intensification (agricultural or livestock) has caused groundwater shifts mainly due to the introduction of exogenous and contaminating microorganisms. The microbial quality of water must be considered as an essential parameter when defining the suitability of the groundwater for animals or rural human consumption, as well as for cleaning the facilities of the dairy. In this study, the objectives were: (1) to determine the microbiological quality of the groundwater in agricultural or livestock farms and, (2) to establish in the studied area the relationship between the land use and groundwater quality. The microbial analyses were performed using several indicators such as: $i$ ) aerobic mesophilic bacteria counts, $i$ ) total and fecal coliforms count, and iii) detection of Escherichia coli and Pseudomonas aeruginosa in groundwater samples obtained from agricultural farms $(E A ; n=28)$ or livestock/dairy farms $(E G ; n=34)$ located in south-central area of Córdoba province, Argentina. At least one microbial indicator over the acceptable limit for human drink or for cleaning dairy farm facilities was detected in the $58 \%$ of studied samples $(n=62)$. The $12 \%$ of the EG demonstrated to have deficient water quality for animal consumption. By bivariate statistical analysis, a scarce relationship was observed between land uses and microbiological water quality indicating that bacterial contamination source is unspecific and probably due to intrinsic factors of the area.
\end{abstract}

\section{INTRODUCCIÓN}

El agua subterránea es un recurso natural esencial en los sistemas agrícolas ganaderos (Blarasín y Cabrera 2005). Representa el suministro seguro de agua potable para la vida del hombre y el sostenimiento de las actividades económicas en ambientes rurales de todo el mundo. Sin embargo, las formas de ocupación del suelo, su estructura y los microorganismos que lo habitan, los flujos de agua y el manejo de efluentes, son algunos factores que condicionan la calidad de los sistemas hidrológicos subterráneos en estos ambientes (Gonzalez et al. 2004, Esterhuizen et al. 2015). Diferentes autores demuestran la vulnerabilidad de este recurso hídrico con cambios drásticos por ejemplo, en los contenidos de nitrógeno (N) o fósforo (P) y en la abundancia y diversidad de especies microbianas presentes como consecuencia de las actividades productivas (Williamson et al. 2008, Valenzuela et al. 2012, Gambero et al. 2017). El aporte de materia orgánica al agua subterránea facilita que se produzcan cambios significativos en las comunidades microbianas nativas y variaciones en su calidad higiénica (Martín 2004) con serias consecuencias en el ambiente y en los seres vivos. El riesgo de contaminación biológica es mayor en áreas de actividad ganadera debido a que los patógenos eliminados a través de las heces y orina de animales pueden ser transportados por infiltración a los cuerpos de agua. Los microorganismos indicadores de contaminación como los coliformes totales
(CT), coliformes fecales (CF), Escherichia coli (E. coli) y Pseudomonas aeruginosa (P. aeruginosa) son frecuentemente empleados como señal de advertencia de una alteración de su calidad (OMS 2012, García y Iannacone 2014).

La provincia de Córdoba se ubica en la región central de Argentina y se extiende en su totalidad en una zona de clima templado. El territorio se caracteriza por un predominio de planicies o llanuras suavemente onduladas y un cordón serrano en la dirección norte. Aproximadamente, la mitad de los suelos de Córdoba (8.3 millones de ha) son aptos para la agricultura, mientras que el $39 \%$ (6.5 millones de ha) cuenta con aptitud variable para la ganadería. El $11 \%$ restante lo ocupan centros poblados y ambientes naturales por lo que se encuentran fuera del mapa agropecuario (Ghida Daza y Sánchez 2009). Por sus características geográficas e hidroclimáticas, en la región centro-sur provincial predominan diversas actividades agrícolas (cultivos intensivos y extensivos) y ganaderas (producción de carne y leche) de gran relevancia económica a nivel nacional. La demanda de agua de estos sistemas productivos es provista casi en su totalidad por el acuífero libre o freático (Blarasin et al. 2014b, Lutri et al. 2016). No obstante, éste es reconocido como el más susceptible a procesos de contaminación difusa en áreas agrícolas (a causa de la aplicación de fertilizantes, plaguicidas, etc.) o puntual en sitios de ganadería intensiva y producción de leche (tambos) (a través de efluentes líquidos o sólidos) (Blarasin et al. 2014b, Giannini 2015). De este modo, la calidad 
microbiológica del agua subterránea en los establecimientos rurales adquiere relevancia debido a que puede ser destinada a diferentes usos: bebida animal, higiene de las instalaciones de los tambos y consumo de la población rural involucrada (Herrero et al. 2002, Blarasin et al. 2014a). Es importante destacar que en Argentina no existen normativas que especifiquen la calidad del agua que se debe utilizar en los tambos. No obstante, se recomienda que cumpla con los mismos parámetros establecidos para agua de consumo humano, según la normativa establecida por el Código Alimentario Argentino (CAA) (Bettera et al. 2011, MSDS 2012). Por otra parte, su cumplimiento es requerido para pertenecer a la categoría de tambo exportador de la Unión Europea, significando una exigencia más para los productores lecheros y convirtiéndose en una barrera arancelaria (Herrero 2014).

En el área agrícola centro-sur de Córdoba, existen escasos estudios que demuestren el efecto de los sistemas agroproductivos sobre el ambiente natural, específicamente en el recurso hídrico subterráneo. En este contexto los objetivos del presente trabajo fueron: (1) conocer la calidad microbiológica del agua subterránea (acuífero freático) en establecimientos agropecuarios de la región centro-sur de Córdoba, a fin de definir aptitudes de uso (para consumo humano, bebida animal e higiene de las instalaciones de ordeñe) y (2) evaluar la relación entre el uso del suelo (área agrícola o ganadera) y la calidad del agua subterránea de la región.

\section{MATERIALES Y MÉTODOS}

\section{Zona de estudio}

La zona en estudio se ubica en la llanura ChacoPampeana Argentina, en el centro-sur de la provincia de Córdoba, entre las coordenadas $32^{\circ} 06^{\prime} 00^{\prime \prime}$ y $32^{\circ} 57^{\prime} 00^{\prime \prime}$ (Latitud Sur) y $64^{\circ} 18^{\prime} 00^{\prime \prime}$ y $62^{\circ} 54^{\prime} 00^{\prime \prime}$ (Longitud Oeste). El área de estudio forma parte de la unidad geomorfológica planicie fluvioeólica central y de la subunidad paleoabanico aluvial del río Ctalamochita (río Tercero) (Carignano et al. 2014). La planicie fluvioeólica central se caracteriza por un paisaje suavemente ondulado dominado por la dinámica de grandes ríos (Suquía, Xanaes, Ctalamochita y Chocancharava) que forman amplios paleoabanicos aluviales donde se reconocen diversos tipos de canales, terrazas, lagunas semicirculares, así como llanuras de inundación abandonadas. El paleoabanico aluvial del río Ctalamochita es el mayor de la planicie fluvioeólica central. Los paleocauces mayores aún funcionan como sistemas independientes drenando parte de la llanura (arroyos Las Junturas, Algodón, Las Mojarras, Cabral, etc.) (Carignano 1999, Carignano et al. 2014).

Este estudio se centró en la cuenca media y alta del arroyo Cabral y abarca una parte importante de la cuenca lechera de Villa María (Córdoba) reconocida a nivel nacional como el tercer conglomerado lechero, en términos de importancia, por su nivel de productividad y calidad de la leche (Taverna y Fariña 2014). Además, en dicho sector predominan campos cultivados con soja, maíz, trigo, maní, forrajes, entre otros, como así también la cría de ganado vacuno, porcino u ovino (en forma extensiva o en unidades de engorde) y tambos. El área total incluida en este estudio posee una superficie aproximada de $850 \mathrm{~km}^{2}$ y abarca a los departamentos General San Martín y Tercero Arriba. La precipitación media anual es de $873 \mathrm{~mm}$ con alternancia de años lluviosos y años secos y el período más húmedo se extiende entre los meses de noviembre a marzo con el $73 \%$ del total anual (Lutri et al. 2016). Los excesos hídricos son de suma importancia ya que a través de procesos de infiltración constituyen la fuente de recarga de los acuíferos.

\section{Toma de muestras}

Se establecieron al azar 62 puntos de muestreo correspondientes a establecimientos rurales de la región que fueron diferenciados, según el uso del suelo, en: establecimientos ganaderos/lecheros (EG, $\mathrm{n}=$ 34) o establecimientos agrícolas (campos cultivados) (EA, n = 28) (Fig. 1). Los muestreos se realizaron entre 2014 y 2016 durante los meses de septiembre a noviembre. Se obtuvieron muestras de perforaciones (bombas extractoras o molinos) que captan agua del acuífero libre (entre los 3 y $30 \mathrm{~m}$ de profundidad), previo purgado de las cañerías (escurrimiento durante $5 \mathrm{~min}$ ). Las muestras se colectaron en recipientes estériles con capacidad de $250 \mathrm{~mL}$, que fueron rotulados y conservados a $4{ }^{\circ} \mathrm{C}$ para su procesamiento inmediato en el laboratorio. Cada establecimiento fue georreferenciado utilizando el sistema de posicionamiento global (GPS) y representado gráficamente utilizando el programa CorelDRAW11.

\section{Procesamiento de las muestras}

Se evaluaron indicadores de contaminación microbiológica mediante la estimación del número de bacterias aerobias mesófilas (BAM), CT, CF y presencia de E. coli y $P$. aeruginosa. Para ello, se siguieron las metodologías establecidas en el manual de técnicas y procedimientos analíticos de la Asociación Americana de Salud Pública (APHA, por sus siglas en inglés 2012). 


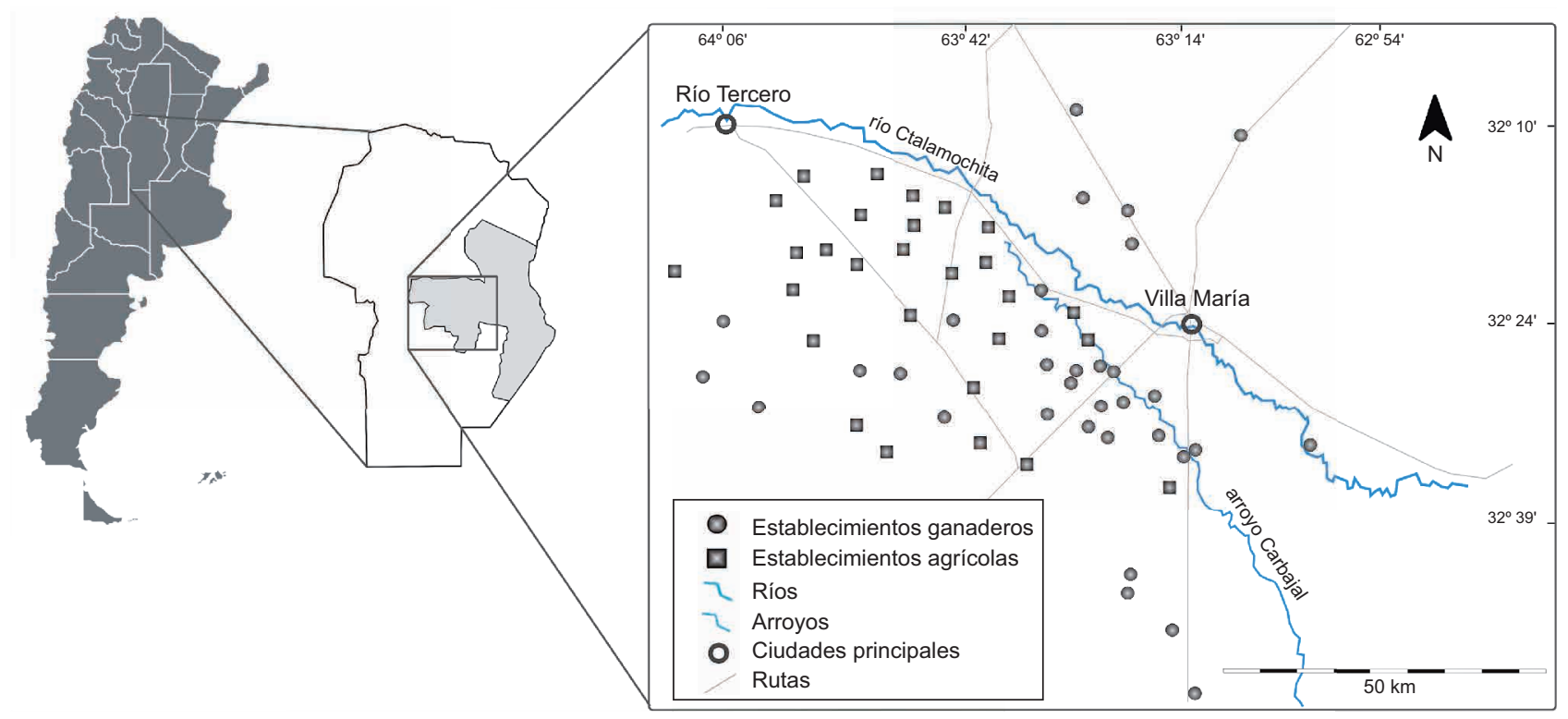

Fig. 1. Ubicación espacial de los establecimientos monitoreados en la región centro-sur de la provincia de Córdoba, Argentina

El recuento de BAM fue determinado mediante el método de siembra en placa en profundidad. A partir de cada muestra de agua se efectuaron diluciones seriadas (1:10), se sembraron alícuotas de $1 \mathrm{~mL}$ en placas de agar para recuento (PCA, BiokarDiagnostics, Argentina) y se incubaron a $35 \pm 2{ }^{\circ} \mathrm{C}$. Luego de 24 - 48 h se contabilizó el número de colonias y los resultados se expresaron como unidades formadoras de colonias por $\mathrm{mL}$ (UFC/mL).

Para la cuantificación de CT y CF se utilizó la técnica de fermentación en tubos múltiples. Para cada muestra se inocularon tres series de cinco tubos con caldo lauril sulfato (Britania, Argentina) y se incubaron a $35 \pm 1{ }^{\circ} \mathrm{C}$ durante $24-48 \mathrm{~h}$. Los tubos que presentaron crecimiento y producción de gas fueron considerados positivos para CT. El resultado se expresó como el número más probable por $100 \mathrm{~mL}$ (NMP/100 mL). Para determinar la cantidad de CF se tomó una asada de los tubos positivos, se inocularon en tubos de medio EC (Britania, Argentina) y se incubaron a $44.5 \pm 1{ }^{\circ} \mathrm{C}$ durante $24 \mathrm{~h}$. Los resultados se expresaron como NMP/100 mL. En cada muestra positiva de CF se confirmó la presencia de E. coli mediante siembra en placas de agar eosina azul de metileno (EMB, Britania, Argentina), que se incubaron a $37^{\circ} \mathrm{C}$ durante $24 \mathrm{~h}$. Las colonias de color negro azulado con brillo metálico se consideraron positivas.

La presencia de $P$. aeruginosa se determinó por la adición de $100 \mathrm{~mL}$ de muestra a igual volumen de caldo asparagina (doble concentración) conteniendo (por litro): L-asparagina (3 g); $\mathrm{K}_{2} \mathrm{HPO}_{4}(1 \mathrm{~g}) ; \mathrm{MgSO}_{4}$
- $7 \mathrm{H}_{2} \mathrm{O}(0.5 \mathrm{~g})$ y se incubó a $35 \pm 2{ }^{\circ} \mathrm{C}$ por $24 \mathrm{~h}$. La confirmación fue realizada en agar acetamida conteniendo (por litro): acetamida (10 g); $\mathrm{NaCl}(5 \mathrm{~g})$; $\mathrm{K}_{2} \mathrm{HPO}_{4}(1.39 \mathrm{~g}) ; \mathrm{KH}_{2} \mathrm{PO}_{4}(0.73 \mathrm{~g}) ; \mathrm{MgSO}_{4} \bullet 7 \mathrm{H}_{2} \mathrm{O}$ $(0.5 \mathrm{~g})$; rojo fenol $(0.012 \mathrm{~g})$; agar bacteriológico (15 g) y se incubó a $35 \pm 2{ }^{\circ} \mathrm{C}$ por $24 \mathrm{~h}$. Las colonias que produjeron el viraje del medio a color rosado se consideraron positivas.

\section{Calidad del agua $\mathrm{y}$ aptitudes de uso}

La calidad microbiológica del agua y sus aptitudes de uso fueron definidas teniendo en consideración las regulaciones nacionales vigentes y publicaciones científicas de referencia. Así, para determinar la aptitud para consumo humano se consideró el criterio de potabilidad establecido por el CAA (MSDS 2012). Este criterio también fue considerado para evaluar el agua destinada a la higiene de los tambos (por ejemplo, el lavado de la máquina de ordeñe) dado que las recomendaciones internacionales sugieren el uso de agua potable para exportar productos lácteos (Herrero 2014). Para los correspondientes análisis de aptitud del agua para consumo de los bovinos lecheros se siguieron las recomendaciones establecidas por Charlón et al. (2002) y Broadwater (2007).

\section{Análisis estadístico}

Se realizó un análisis estadístico exploratorio de los datos obtenidos para todos los parámetros microbiológicos en las muestras de agua subterránea; las variables continuas se resumen como media \pm 
desviación estándar y rango, y las categóricas como frecuencia porcentual (Valenzuela et al. 2009).

Con el fin de evaluar diferencias estadísticas en la calidad microbiológica del agua entre los parámetros analizados para los distintos puntos de muestreo y el tipo de uso del suelo (EG o EA) se realizaron análisis bivariados a través del cálculo de estadísticos agrupados, coeficientes de contingencia (C) y razón de momios (RM). El valor C permite establecer el grado de asociación entre dos variables cualitativas, pudiendo $0 \leq \mathrm{C} \leq 1(\mathrm{C}=0$ independencia; $\mathrm{C}=1$ asociación perfecta). Mientras que la RM indica la probabilidad de ocurrencia de un evento y su interpretación no es absoluta, sino relativa (Frutos 2010, RodríguezÁlvarez et al. 2017). Para obtener los resultados se utilizó el paquete estadístico IBM SPSS Statistics V.23 (IBM Corp., Armonk, N.Y., USA).

\section{RESULTADOS Y DISCUSIÓN}

\section{Calidad del agua para consumo humano}

Dada la importancia del agua subterránea en los sistemas agropecuarios de la región centro-sur de Córdoba, se evaluó la calidad microbiológica de este recurso considerando los criterios de potabilidad establecidos por el CAA (MSDS 2012). La figura 2 representa la ubicación espacial de todos los establecimientos monitoreados $(n=62)$ respecto de su aptitud para consumo humano. Del total de muestras analizadas, el $42 \%$ calificaron como aptas para consumo humano, mientras que el $58 \%$ restante no cumplió con al menos uno de los parámetros establecidos por la regulación vigente. Cabe destacar que en las cercanías del arroyo Cabral la mayoría de

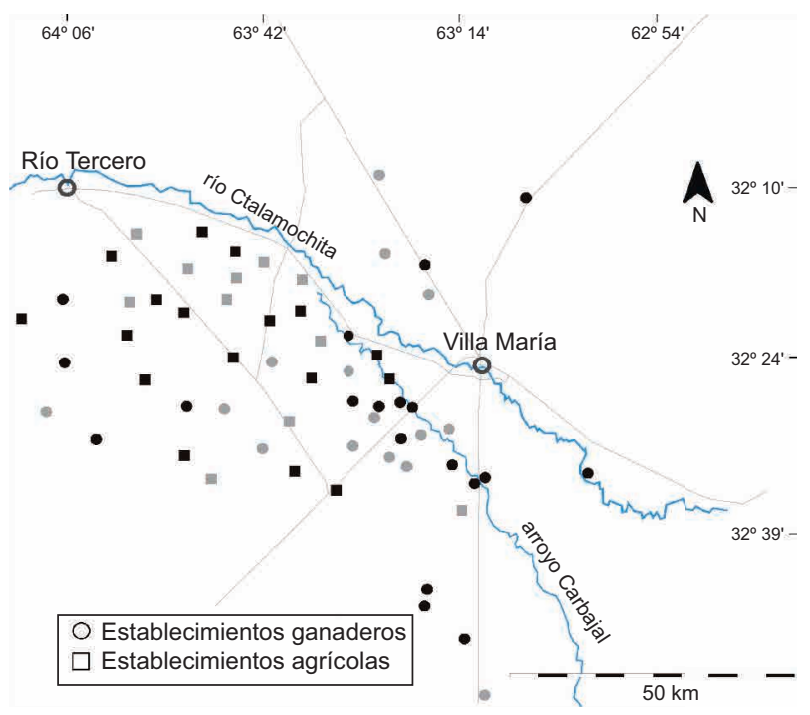

Fig. 2. Distribución espacial de los establecimientos monitoreados según la aptitud para consumo humano en la región centro-sur de la provincia de Córdoba, Argentina. En color gris se establecen muestras aptas para consumo humano en relación a los indicadores microbiológicos y en color negro se establecen muestras no aptas (MSDS 2012)

las muestras resultaron no aptas para este uso. Estudios geológicos de la zona realizados por Lutri et al. (2016) revelaron que en cercanías de la faja fluvial del arroyo Cabral, la profundidad del nivel freático es muy variable ( 1 a $26 \mathrm{~m}$ ). Este aspecto permite determinar la mayor vulnerabilidad del sistema a procesos de degradación.

El $24 \%$ de las muestras superaron el valor límite establecido para recuento de BAM $(<500 \mathrm{UFC} / \mathrm{mL})$ (Cuadro I) lo que demuestra una alteración del

CUADRO I. PORCENTAJE DE MUESTRAS NO APTAS PARA LOS PARÁMETROS MICROBIOLÓGICOS ESTABLECIDOS PARA CONSUMO HUMANO SEGÚN EL CAA (MSDS 2012) EN ESTABLECIMIENTOS AGRÍCOLAS (EA) Y ESTABLECIMIENTOS GANADEROS (EG) DE LA REGIÓN CENTRO-SUR DE LA PROVINCIA DE CÓRDOBA, ARGENTINA

\begin{tabular}{|c|c|c|c|c|c|c|c|}
\hline \multirow{2}{*}{$\begin{array}{l}\text { Parámetros } \\
\text { microbiológicos }\end{array}$} & \multirow{2}{*}{$\begin{array}{l}\text { Valor límite } \\
\text { (MSDS, 2012) }\end{array}$} & \multicolumn{2}{|c|}{$\mathrm{EA}(\mathrm{n}=28)$} & \multicolumn{2}{|c|}{$\mathrm{EG}(\mathrm{n}=34)$} & \multicolumn{2}{|c|}{ Total $(n=62)$} \\
\hline & & $\begin{array}{c}\text { No aptas } \\
\left(\mathrm{N}^{\circ}\right)\end{array}$ & $\begin{array}{c}\text { Frecuencia } \\
\quad(\%)\end{array}$ & $\begin{array}{c}\text { No aptas } \\
\left(\mathrm{N}^{\circ}\right)\end{array}$ & $\begin{array}{c}\text { Frecuencia } \\
(\%)\end{array}$ & $\begin{array}{c}\text { No aptas } \\
\left(\mathrm{N}^{\circ}\right)\end{array}$ & $\begin{array}{c}\text { Frecuencia } \\
(\%)\end{array}$ \\
\hline BAM & $<500 \mathrm{UFC} / \mathrm{mL}$ & 7 & 25 & 8 & 23 & 15 & 24 \\
\hline $\mathrm{CT}$ & $<3 \mathrm{NMP} / 100 \mathrm{~mL}$ & 11 & 39 & 8 & 23 & 19 & 31 \\
\hline $\mathrm{CF}$ & $<3 \mathrm{NMP} / 100 \mathrm{~mL}$ & 3 & 11 & 2 & 6 & 5 & 8 \\
\hline E. coli & Ausencia/100 mL & 3 & 11 & 2 & 6 & 5 & 8 \\
\hline P. aeruginosa & Ausencia/100 mL & 11 & 39 & 15 & 44 & 26 & 42 \\
\hline
\end{tabular}

$\mathrm{BAM}=$ bacterias aerobias mesófilas, $\mathrm{CT}=$ coliformes totales, $\mathrm{CF}=$ coliformes fecales, $\mathrm{UFC}=$ unidades formadoras de colonias, NMP = número más probable 
estado general del agua. El consumo de agua con elevados recuentos de BAM puede causar enfermedades como gastroenteritis, infecciones de la piel y de membranas mucosas en personas inmunodeprimidas (OMS 2016). Con respecto al indicador CT, el $31 \%$ de las muestras analizadas superaron el valor límite $(<3 \mathrm{NMP} / 100 \mathrm{~mL})$, confirmándose el origen fecal de la contaminación sólo en el $8 \%$ de las muestras (CF y presencia de $E$. coli). Las fuentes de contaminación del agua con bacterias coliformes pueden ser diversas, incluyendo el agua de drenaje desde los lotes de encierro de los animales, la aplicación de abonos orgánicos y las filtraciones provenientes desde las lagunas de efluentes o tanques sépticos.

Entre las muestras no aptas, una alta proporción (42\%) no cumplió con el criterio de potabilidad establecido para $P$. aeruginosa (ausencia/100 mL). Esta bacteria es un patógeno oportunista por excelencia y el principal agente etiológico de infecciones en vías urinarias, intestino, oído y heridas (Apella y Araujo 2005). Su fuente primaria es el agua y el suelo debido a su versatilidad respecto a las fuentes de carbono y a sus bajos requerimientos nutricionales (Moore et al. 2002, Herrero 2014, Kopp et al. 2015). Su presencia en las muestras analizadas podría atribuirse al incremento de las precipitaciones ocurridas en la región durante el período de muestreo (superando en el año 2015 hasta en $90 \mathrm{~mm}$ la media anual). El anegamiento de los suelos, el ascenso del nivel de agua del acuífero freático, conjuntamente con los procesos de infiltración serían los factores más importantes que favorecieron la llegada de estos microorganismos al acuífero, provocando su contaminación.

\section{Calidad del agua para abrevado del ganado bovi- no y limpieza de las instalaciones de ordeñe}

Los animales en ordeñe requieren una alta disponibilidad de agua de bebida en cantidad y calidad con relación al peso corporal (consumo superior a $150 \mathrm{~L} /$ día), debido a que ésta representa un $87 \%$ de la composición final de la leche producida (Bavera 2001, Fernández Cirelli et al. 2010). En general, los bovinos son poco sensibles a la contaminación microbiológica del agua de consumo por su condición de rumiantes. Sin embargo, una elevada carga microbiana puede provocar problemas de salud especialmente en la etapa de prerumiante (terneros) (Herrero et al. 2002).

En los EG monitoreados $(\mathrm{n}=34)$, los recuentos de BAM no superaron el valor límite establecido $(<10000 \mathrm{UFC} / \mathrm{mL})$ según Charlón et al. (2002) y Broadwater (2007). Sin embargo, el $15 \%$ de las muestras superaron los límites recomendados para los recuentos de CT $(<15 \mathrm{NMP} / 100 \mathrm{~mL})$, de las cuales el $6 \%$ superaron el valor límite para CF (< $10 \mathrm{NMP} / 100 \mathrm{~mL}$ ) (Broadwater 2007) evidenciando una calidad bacteriológica deficiente.

$E$. coli y $P$. aeruginosa poseen la capacidad de colonizar las superficies de los equipos de ordeñe y mangueras, generando biopelículas que favorecen su adherencia y la protección frente a agentes desinfectantes, convirtiéndose en una fuente de contaminación para la leche (Iramain et al. 2005, Raats et al. 2011). En los EG monitoreados, $P$. aeruginosa ha sido detectada en el $44 \%$ de las perforaciones, siendo superior al valor hallado en tambos de la provincia de Buenos Aires, Argentina (con un $27 \%$ de muestras positivas) (Iramain et al. 2005). Un estudio realizado por Herrero (2014) demostró que las bacterias aportadas por el agua de lavado, entre ellas $P$. aeruginosa, quedan adheridas a la piel de los pezones pudiendo contaminar la leche. A partir de estos antecedentes, resulta esencial la eliminación de estas bacterias de la fuente de agua y equipos de ordeñe, mediante métodos de desinfección tales como la cloración del agua y la limpieza periódica de los tanques de almacenamiento. Dichas prácticas, poco utilizadas en los tambos, son importantes para controlar no sólo la contaminación de ubres y equipos, sino también de la leche cruda y la posible aparición de brotes de mastitis (Iramain et al. 2005).

\section{Relación entre la calidad del agua y el uso del suelo}

Las actividades agrícolas y ganaderas constituyen importantes fuentes de contaminación microbiológica de los acuíferos freáticos.

Dentro de los parámetros analizados, las coliformes son un grupo de bacterias que se pueden encontrar en el agua pudiendo causar problemas para la salud tanto humana como animal. Considerando el uso del suelo, los recuentos de CT en las muestras analizadas superaron el valor límite para consumo humano en el $39 \%$ de los EA y en el $23 \%$ de los EG (Cuadro I), siendo el valor medio de estos últimos, superior al obtenido en los EA (55.18 \pm $273.73 \mathrm{NMP} / 100 \mathrm{~mL}$ ). Para CF, el $11 \%$ de los EA y el $6 \%$ de los EG superaron el límite establecido por el CAA (MSDS 2012) con valores medios de 6.5 $\pm 18.08 \mathrm{NMP} / 100 \mathrm{~mL}$ y $2.13 \pm 2.51 \mathrm{NMP} / 100 \mathrm{~mL}$, respectivamente (Cuadro II). El grupo de CT incluye una amplia variedad de bacterias tanto entéricas como ambientales, en consecuencia, su presencia no necesariamente se relaciona con contaminación fecal sino con la carga total de bacterias dentro del acuífero (Cullimore 2007). Contrariamente, las CF son de origen exclusivamente intestinal, por lo que su presencia está relacionada con la contaminación 
CUADRO II. ESTADÍSTICA DESCRIPTIVA(MEDIA, DESVIACIÓN ESTÁNDAR (DE) Y RANGO) DE LOS INDICADORES MICROBIOLÓGICOS CUANTITATIVOS (RECUENTO DE BAM, CT Y CF), CLASIFICADOS SEGÚN EL USO DEL SUELO

\begin{tabular}{|c|c|c|c|c|c|c|c|c|c|c|}
\hline \multirow{2}{*}{$\begin{array}{l}\text { Uso del } \\
\text { Suelo }\end{array}$} & \multirow{2}{*}{$\begin{array}{c}\mathrm{N}^{\mathrm{o}} \mathrm{de} \\
\text { muestras }\end{array}$} & \multicolumn{3}{|c|}{ Recuento de BAM (UFC/mL) } & \multicolumn{3}{|c|}{$\mathrm{CT}(\mathrm{NMP} / 100 \mathrm{~mL})$} & \multicolumn{3}{|c|}{$\mathrm{CF}(\mathrm{NMP} / 100 \mathrm{~mL})$} \\
\hline & & Media & $\mathrm{DE}$ & Rango & Media & $\mathrm{DE}$ & Rango & Media & $\mathrm{DE}$ & Rango \\
\hline EA & 28 & 741.21 & 1759.26 & $10-6900$ & 38.91 & 108.91 & $1.5-480$ & 6.5 & 18.08 & $1.5-93$ \\
\hline EG & 34 & 377.24 & 589.37 & $15-2050$ & 55.18 & 273.73 & $1.5-1600$ & 2.13 & 2.51 & $1.5-12$ \\
\hline
\end{tabular}

$\mathrm{BAM}=$ bacterias aerobias mesófilas, $\mathrm{CT}=$ coliformes totales, $\mathrm{CF}=$ coliformes fecales, $\mathrm{UFC}=$ unidades formadoras de colonias, $\mathrm{NMP}=$ número más probable

fecal, incluyendo géneros bacterianos potencialmente patógenos. En este estudio, E. coli se detectó sólo en el $8 \%$ del total de los establecimientos analizados, encontrándose con mayor frecuencia en EA (11 \%).

En este estudio, el análisis de contingencia (Cuadro III) no reveló asociación con significancia estadística $(\mathrm{C}=0.049 ; \mathrm{p}=0.701)$ entre el uso del suelo y la aptitud de la calidad del agua (por ejemplo: consumo humano, consumo animal, limpieza de instalaciones, etc.). No obstante, se demostró previamente que una alta proporción de las muestras de agua subterránea analizadas (58 \%) no resultaron aptas para consumo humano.

El cuadro III muestra además el análisis de correlación entre la presencia de E. coli o P. aeruginosa y el tipo de uso del suelo (EG o EA) mediante un análisis de datos bivariado. Si bien los resultados no demuestran una asociación significativa entre la presencia de $E$. coli y el uso del suelo $(\mathrm{C}=0.088$; $\mathrm{p}=0.49$ ), la probabilidad de encontrar esta especie

CUADRO III. ANÁLISIS BIVARIADOS DE LAS VARIABLES CATEGÓRICAS EN FUNCIÓN DEL USO DEL SUELO

\begin{tabular}{lll}
\hline Variables & & $\begin{array}{c}\text { Uso del suelo } \\
\text { (EA/EG) }\end{array}$ \\
\hline Aptitud para & $\mathrm{C}$ & 0.049 \\
consumo humano & $\mathrm{RM}$ & 1.22 \\
& $\mathrm{p}$-valor & 0.701 \\
\hline E. coli & $\mathrm{C}$ & 0.088 \\
& $\mathrm{RM}$ & 1.92 \\
& $\mathrm{p}$-valor & 0.487 \\
\hline P. aeruginosa & $\mathrm{C}$ & 0.049 \\
& $\mathrm{RM}$ & 1.22 \\
& $\mathrm{p}$-valor & 0.701 \\
\hline
\end{tabular}

$\mathrm{C}=$ coeficiente de contingencia, $\mathrm{RM}=$ razón de momios, p-valor $<0.05$ en aguas de EA es casi dos veces mayor que en $\mathrm{EG}(\mathrm{RM}=1.92)$. Entre las muestras analizadas se detectó $P$. aeruginosa en el $44 \%$ de los EG y en el $39 \%$ de los EA. La probabilidad de encontrar esta bacteria en EG es un $22 \%$ mayor que en EA $(\mathrm{RM}=1.22)$ aunque su presencia no mostró correlación significativa con el tipo de uso de suelo $(\mathrm{C}=0.049 ; \mathrm{p}=0.701)$.

En este estudio no se efectuó un relevamiento sobre la existencia y ubicación de posibles focos de contaminación que podrían favorecer la llegada de contaminantes al acuífero, por lo cual resulta difícil conocer el origen de la contaminación detectada. En los EG la contaminación del acuífero freático con CF se relaciona directamente al tipo de actividad que en estos se desarrolla, debido a la cercanía de la perforación a lotes con una alta carga animal o a filtraciones provenientes de las lagunas de efluentes (Valenzuela et al. 2012, Giuliano Albo et al. 2015). Por otra parte, determinadas prácticas desarrolladas en los EA también pueden incidir en la contaminación de los acuíferos especialmente cuando se utiliza abono de estiércol o aguas residuales de origen ganadero como fertilizantes orgánicos. Además, los fertilizantes pueden infiltrarse y aportar nutrientes al agua subterránea favoreciendo el desarrollo bacteriano (Martín 2004, Lopez-Velasco et al. 2012). La calidad microbiana del agua subterránea también puede verse afectada por otros factores como deficiencias en la ubicación y construcción de los pozos y la presencia de asentamientos humanos que favorezcan el aporte de material cloacal (pozos negros, cámaras sépticas). El volumen y frecuencia de las precipitaciones y la profundidad del acuífero freático también juegan un rol determinante (Gerba 2009). Más estudios deben realizarse en la región, a efectos de analizar nuevos parámetros que puedan estar íntimamente asociados a cambios en la calidad del acuífero.

Cabe señalar que, en un estudio realizado por Bettera et al. (2011) en establecimientos lecheros de 
la cuenca de Villa María, se informaron para agua de pozo porcentajes similares para BAM (24\%), una mayor incidencia de CT y E. coli $(80$ y $20 \%$, respectivamente) y una menor presencia de $P$. aeruginosa $(36 \%)$ con respecto a los presentados en este trabajo. En la cuenca lechera del Abasto Sur (Buenos Aires, Argentina), Herrero et al. (2002) reportaron valores menores de BAM (11.86 \% de las perforaciones) a los informados en este estudio, mientras que los recuentos de CT y E. coli fueron superiores (57.62 \% y $25.42 \%$, respectivamente). Finalmente, los autores informaron que en el $23.72 \%$ de los pozos hay presencia de $P$. aeruginosa.

\section{CONCLUSIONES}

Las actividades productivas que se desarrollan en la región centro-sur de Córdoba generan un fuerte impacto en la calidad del agua subterránea. Los resultados obtenidos evidenciaron que una alta proporción de establecimientos agropecuarios disponen de agua no apta microbiológicamente para los diferentes usos a la que se la destina en zonas rurales. Las deficiencias de calidad se deben principalmente a recuentos que superan los límites admitidos para bacterias indicadoras como coliformes y/o a la presencia de P. aeruginosa.

Los problemas de contaminación del agua subterránea detectados en este estudio no se asociaron directamente con el tipo de uso del suelo, sino que existen en la región otros factores condicionantes. Esto último es de gran relevancia y debe alertar a las autoridades locales sobre el impacto ambiental al que están expuestos los recursos hídricos de la región bajo la influencia de los sistemas agropecuarios. Es un desafío profundizar este trabajo mediante el estudio de nuevas variables que permitan identificar probables causas involucradas en los cambios de calidad de la fuente de agua.

En conjunto, los conocimientos generados en este trabajo de investigación sientan bases para que los organismos gubernamentales profundicen las políticas de control y seguimiento de las diversas actividades productivas, a fin de proteger las principales reservas de agua dulce.

\section{AGRADECIMIENTOS}

Los autores agradecen a los productores agropecuarios participantes, a la Cámara de Productores Lecheros de Córdoba (CAPROLEC) y al grupo de investigación de la Dra. Mónica Blarasin (Laboratorio de Hidrogeología, Universidad Nacional de Río Cuarto) por su colaboración en este trabajo. Esta investigación fue financiada con fondos otorgados por el Instituto de Investigación (Universidad Nacional Villa María) y la Secretaría de Políticas Universitarias (Ministerio de Educación de la Nación).

\section{REFERENCIAS}

APHA (2012). Standard methods for the examination of water and wastewater. $22^{\mathrm{a}}$ ed. American Public Health Association. Washington, EUA, 1360 pp.

Apella M. C. y Araújo P. Z. (2005). Microbiología de agua. Conceptos básicos. En: Tecnologías solares para la desinfección y descontaminación del agua (M. A. Blesa y J. Blanco-Gálvez, Eds.). Universidad Nacional de General San Martín, Buenos Aires, Argentina, pp. 27-44.

Bavera G. (2001). Manual de aguas y aguadas para el ganado. $2^{\text {da }}$ ed. Gráfica del Sur SRL Ed. Río Cuarto, Argentina, $387 \mathrm{pp}$.

Bettera S. G., Dieser S. A., Vissio C., Geuna G., Díaz C., Larriestra A. J. y Frigerio C. (2011). Calidad microbiológica del agua utilizada en establecimientos lecheros de la zona de Villa María (Córdoba). Rev. Argent. Microbiol. 43 (2), 111-114.

Blarasín M. y Cabrera A. (2005). Agua subterránea y ambiente. Agencia Córdoba Ciencia, Córdoba, Argentina, $32 \mathrm{pp}$.

Blarasin M., Cabrera A., Matteoda E., Felizzia J., Maldonado L., Bécher-Quinodóz F. N. y Giuliana-Albo J. (2014a). Cuadernos de estudios de aguas subterráneas: el agua subterránea y la actividad ganadera-tambera. UniRío Editora, Río Cuarto, Argentina, 45 pp.

DOI: $10.13140 / 2.1 .3652 .3846$

Blarasin M., Cabrera A. y Matteoda E. (2014b). Aguas subterráneas de la provincia de Córdoba. UniRío Editora, Río Cuarto, Argentina, $147 \mathrm{pp}$.

DOI: $10.13140 / 2.1 .1686 .3049$

Broadwater N. (2007). What if cows don't drink enough water?. University of Minnesota Extension, EUA. [en línea]. http://www.thebeefsite.com/articles/1223/whatif-cows-dont-drink-enough-water-part-2/ 15/11/2017

Carignano C. (1999). Late Pleistocene to recent climate change in Córdoba province, Argentina: geomorphological evidence. Quater. Int. 57-58: 117-134. DOI: 10.1016/S1040-6182(98)00054-8

Carignano C., Kröhling D., Degiovanni S. y Cioccale M. (2014). Geomorfología de la provincia de Córdoba (Argentina). Memorias. Relatorios del XIX Congreso Geológico Argentino. Córdoba, Argentina. 2 al 6 de junio, 2014. 747-821 pp. 
Charlón V., Taverna M. A. y Herrero M. A. (2002). El agua en el tambo. En: Manual de referencia para el logro de leche de calidad. (Instituto Nacional de Tecnología Agropecuaria Rafaela, Ed). Rafaela, Argentina, pp. 43-54.

Cullimore D. R. (2007). Practical manual of groundwater microbiology. $2^{\text {nd }}$ ed. Taylor and Francis Group, Florida, EUA, 377 pp.

Esterhuizen L., Fossey A. y Potgieter E. (2015). Groundwater quality on dairy farms in central South Africa. Water SA 41 (2), 194-198. DOI: 10.4314/wsa.v41i2.04

Fernández Cirelli A., Schenone N., Pérez Carrera A. y Volpedo A. (2010). Calidad de agua para la producción de especies animales tradicionales y no tradicionales en Argentina. Revista Augmdomus 1, 45-66.

Frutos P. (2010). Valoración de la calidad del agua de abastecimiento: medidas defensivas frente a disposición a pagar por su mejora. Urban Public Econ. Rev. 13, 34-65.

Gambero M. L., Blarasin M., Bettera S. y Albo J. G. (2017). Genetic diversity of Escherichia coli isolates from surface water and groundwater in a rural environment. J. Water Health 15 (5), 757-765.

DOI: $10.2166 /$ wh.2017.281

García L. e Iannacone J. (2014). Pseudomonas aeruginosa un indicador complementario de la calidad de agua potable. The Biologist 12 (1), 133-152.

Gerba C. P. (2009). The role of water and water testing in produce safety. En: Microbial safety of fresh produce. (X. Fan, B.A. Niemira, C.J. Doona, F.E. Feeherry, R.B. Gravani, Eds.). Wiley-Blackwell, Ames, EUA, pp. 129-142. DOI: 10.1002/9781444319347.ch7

Ghida Daza C. y Sánchez C. (2009). Zonas agroeconómicas homogéneas: Córdoba. Instituto Nacional de Tecnología Agropecuaria, Buenos Aires, Argentina, $258 \mathrm{pp}$.

Giannini F. (2015). Caracterización del recurso hídrico subterráneo de la provincia de Córdoba. Tesis de Licenciatura. Facultad de Ciencias Agropecuarias, Universidad Nacional de Córdoba. Córdoba, Argentina, 22 pp.

Giuliano Albo M. J., Blarasin M. y Panarello H. (2015). Evaluación de la geoquímica e isótopos del nitrato en el acuífero libre de una llanura con actividad agropecuaria, Córdoba, Argentina. Ingeniería 19 (1), 24-38.

Gonzalez M. L., Lopez D. A. y Gatica C. (2004). Effect of soil-use on deep groundwater quality in Southern Chile. Int. J. Environ. Pollut. 21 (3), 240-252.

DOI: 10.1504/IJEP.2004.004192

Herrero M. A. (2014). Uso y manejo del agua y efluentes en un área rural: consecuencias sanitarias y ambientales de la intensificación de la producción primaria de leche. Tesis de Doctorado. Facultad de Farmacia y Bioquímica, Universidad de Buenos Aires. Buenos Aires, Argentina, 380 pp.
Herrero M., Iramain M., Korol S., Buffoni H., Flores M., Pol M. y Fortunato M. (2002). Calidad de agua y contaminación en tambos de la cuenca lechera de Abasto Sur, Buenos Aires, Argentina. Rev. Arg. Prod. Anim. 22 (1), 61-70.

Iramain M. S., Pol M., Korol S., Herrero M. A., Fortunato M. S., Bearzi C. y Maldonado May V. (2005). Pseudomonas aeruginosa en agua y leche cruda: informe preliminar. Rev. InVet 7 (1), 133-137.

Kopp S. B., Pérez M. A., García S. D. y Patiño S. M. (2015). Calidad microbiológica del agua de bebida para cerdos: análisis comparativo en establecimientos porcinos de la zona núcleo de la provincia de Córdoba. Rev. Senasa 9, 15-20.

Lopez-Velasco G., Sbodio A., Tomás-Callejas A., Wei P., Tan K. H. y Suslow T. V. (2012). Assessment of root uptake and systemic vine-transport of Salmonella enterica sv. Typhimurium by melon (Cucumismelo) during field production. Int. J. Food Microbiol. 158 (1), 65-72.

DOI: 10.1016/j.ijfoodmicro.2012.07.005

Lutri V., Matteoda E. y Blarasín M. (2016). Cuadernos de uso y manejo de aguas subterráneas. Cuenca alta y media del arroyo Cabral, Córdoba, Argentina - Aptitudes de uso del acuífero freático. UniRío Editora, Río Cuarto, Argentina, 24 pp.

Martín I. (2004). Riesgo sanitario por presencia de Peudomonasa eruginosa en el agua para consumo. Tesis de Licenciatura. Universidad Nacional de General Sarmiento. Buenos Aires, Argentina, 53 pp.

MSDS (2012). Código Alimentario Argentino. Capítulo XII - Bebidas hídricas, agua y agua gasificada. Agua Potable. Ministerio de Salud y Desarrollo Social. Administración Nacional de Medicamentos, Alimentos y Tecnología Médica. Octubre de 2012.

Moore J. E., Heaney N., Millar B. C., Crowe M. y Elborn J. (2002). Incidence of Pseudomonas aeruginosa in recreational and hydrotherapy pools. Commun. Dis. Public Health 5 (1), 23-26.

OMS (2012). Guías de la OMS para la calidad del agua potable. $3^{\text {a }}$ ed. World Health Organization. Ginebra, Suiza, 408 pp.

OMS (2016). Reglamento Sanitario Internacional (2005). $3^{\text {a }}$ ed. World Health Organization. Ginebra, Suiza, $104 \mathrm{pp}$.

Raats D., Offek M., Min D. y Halper M. (2011). Molecular analysis of bacterial communities in raw cow milk and the impact of refrigeration on its structure and dynamics. Food Microbiol. 28 (3), 465-471.

DOI: $10.1016 /$ j.fm.2010.10.009

Rodríguez-Alvarez M. S., Moraña L. B., Salusso M. M., Gil J. y Seghezzo L. (2017). Utilidad de los registros sanitarios locales para vincular la tasa de incidencia 
de diarreas con la calidad del agua de consumo. Rev. Argent. Microbiol. 50 (4), 374-379.

DOI: 10.1016/j.ram.2017.09.003

Taverna M. y Fariña S. (2014). La producción de leche en Argentina. Anuario de la lechería Argentina. Fundación para la promoción y el desarrollo de la cadena láctea argentina (FunPEL). Buenos Aires, Argentina, 43 pp. Valenzuela E., Godoy R., Almonacid L. y Barrientos M. (2012). Calidad microbiológica del agua de un área agrícola-ganadera del centro sur de Chile y su posible implicancia en la salud humana. Rev. Chil. Infectol. 29 (6), 628-634.

DOI: $10.4067 / \mathrm{S} 0716-10182012000700007$
Valenzuela M., Lagos B., Claret M., Mondaca M., Pérez C. y Parra O. (2009). Fecal contamination of groundwater in a small rural dryland watershed in central Chile. Chil. J. Agr. Res. 69 (2), 235-243. DOI: $10.4067 / \mathrm{S} 0718-58392009000200013$

Williamson C. E., Dodds W., Kratz T. K. y Palmer M. A. (2008). Lakes and streams as sentinels of environmental change in terrestrial and atmospheric processes. Front. Ecol. Environ. 6 (5), 247-254.

DOI: $10.1890 / 070140$ 